\title{
Strain Research of Floating Bridge Side Joints in Lab Loading Tests
}

\author{
Wiesław Krason ${ }^{1, a^{*}}$, Paweł Bogusz ${ }^{1, b}$ \\ ${ }^{1}$ Faculty of Mechanical Engineering, Military University of Technology, \\ 00-908 Warsaw, Witolda Urbanowicza Street 2, Poland \\ awieslaw.krason@wat.edu.pl, bpawel.bogusz@wat.edu.pl
}

Keywords: Floating Bridge, 3-Point Bending Test, Digital Image Correlation Method, Experimental Mechanics

\begin{abstract}
The separated main connector of a prototype cassettes floating bridge, composed of a mandrel and an outer sleeve, is the subject of the experimental research presented in the work. Operating conditions, similar to those found in side connectors and in the roadway surface of a real joint prototype, are mapped during the lab tests. Determination of strain maps of the prototype joint sleeve walls is the purpose of these tests. Strength tests of the three-point bending of the separated bridge side connector were preceded by a preliminary strength analysis with the use of analytical models and FEM analysis. The range of loads used is selected in such a manner that the maximum stress occurring in the joint sleeve walls should not exceed the yield strength of the material. The electroresistance gauge method is supplemented with the optical image correlation methods for deformation measurements. With a continuous strain distribution maps are developed in this manner. The strain maps enabled a precise identification of the most stressed areas in the joint sleeve wall during the bending tests, as well as a strength assessment of the structural solution of the blind screw fixing mandrel in the connector sleeve.
\end{abstract}

\section{Introduction}

Crossing bride constructions of various types are of great importance for the modern army mobility. They are successively developed, researched and implemented [1, 2, 3]. Modern armies are equipped with pontoon floating bridges $[1,4]$. These structures are applicable both to the needs of the army and civilians. They enable organizing temporary crossings on rivers and various water reservoirs. Bridges of this type are used, among others, in places where fixed bridges are excluded from repair, due to, for example, operational damage. To replace the damaged bridge, a substitute floating bridge from individual modules, suitable for the organized crossing is assembled [4]. Floating modules are used in conditions of natural disasters, e.g. during a flood. Undoubted advantages of this type of construction include the simplicity of the structure and the ability to organize various construction shapes depending on the water crossing characteristics. The advantage of floating bridges is also a possibility to use them regardless of the water obstacle depth and in various terrain conditions [1, 4].

The existing structural solutions of floating bridges are not able to meet the current requirements. Hence, a need to modernize crossing equipment emerges. Typical and outdate pontoon bridge constructions (e.g. PP-64 system) consist of a series of hermetic metal floating modules of large dimensions and complicated structure. Therefore, there are problems related to transport of well qualified operating teams. The restrictions to the usage of this type of heavy structure also result from operating conditions in a demanding environment. The use of steel pontoons with large dimensions requires adequate storage conditions and a sufficiently large storage space. These requirements are fulfilled by the structure of an innovative ribbon

(c) (1) Content from this work may be used under the terms of the Creative Commons Attribution 3.0 license. Any further distribution of this work must maintain attribution to the author(s) and the title of the work, journal citation and DOI. Published under license by Materials Research Forum LLC. 
assembled from a floating cassette pontoon bridge, proposed by the team of the Department of Mechanics and Applied Computer Science of the Military University of Technology, [4, 5, 6, 7].

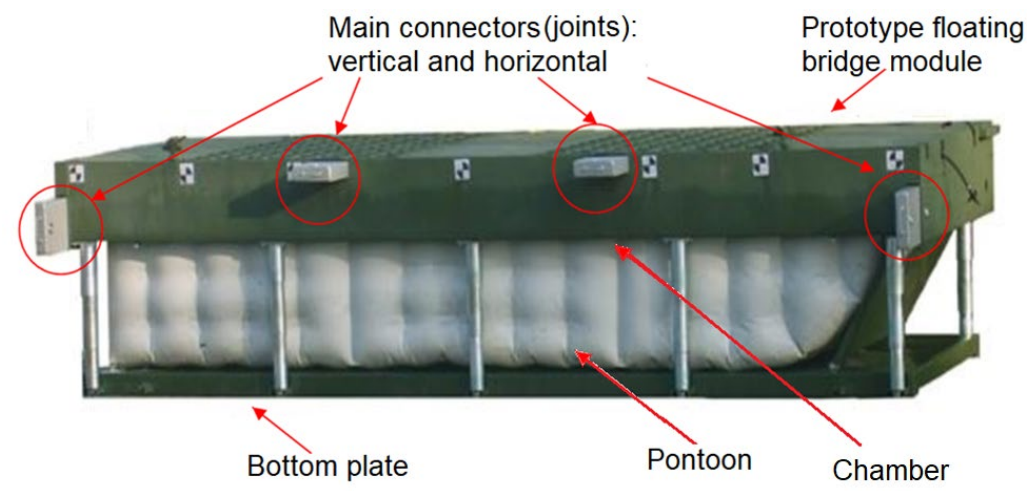

Fig. 1. A module of a prototype floating bridge with the location of main joints set vertically and horizontally on a side of the construction

Figure 1 shows a prototype floating cassette in which the bottom plate can be moved by pressure of a flexible pontoon operated inside a chamber on the bottom of the cassette. The analysed floating cassettes can be used, as all types of floating systems, in the form of footbridges, bridges, rafts or various types of jetties and quays. For special applications for the needs of an army, the cassettes should be assembled in the ribbon bridge. An unquestionable advantage of the cassette is regulation of the submersion which provides a possibility to leave the connected floating bridge below the water surface, which is the advantage of covering up the crossing a cross a river for, e.g., an enemy army. A re-use and return of the bridge to the water surface requires filling a flexible pontoon with the compressed air. A bridge built of pontoon cassettes can be assembled quickly and used as a substitute crossing organized in places where fixed bridges are not in service.

The main objective of this paper is to investigate strain maps of the floating bridge joint element with a usage of optical deformation measurement system. Similar investigations were carried out in [8], where the strength of a separated subsystem of a wagon for transport of trucks semitrailers is evaluated. The designed wagon allows easy and independent loading, transport and unloading without any special equipment or an additional platform infrastructure. The tests presented in paper [8] concern a wagon separated construction element - a side lock the most strained part of the wagon. Owing to the application of a non-contact optical system of strains measurement, the lock deformations as well as the areas of the minimum and maximum main deformations were defined.

\section{Object of the research}

The subject of the experimental research presented in this work is a separated main connector (joint) presented in Figure 2. There are four connectors on the both sides of each module of the floating bridge. Two are placed vertically and two - horizontally (Fig. 1). Side main connectors play an important role in the operation of the floating bridge [1, 4, 7]. They enable fast and easy connection of identical floating modules for assembling a complex ribbon of the bridge. 


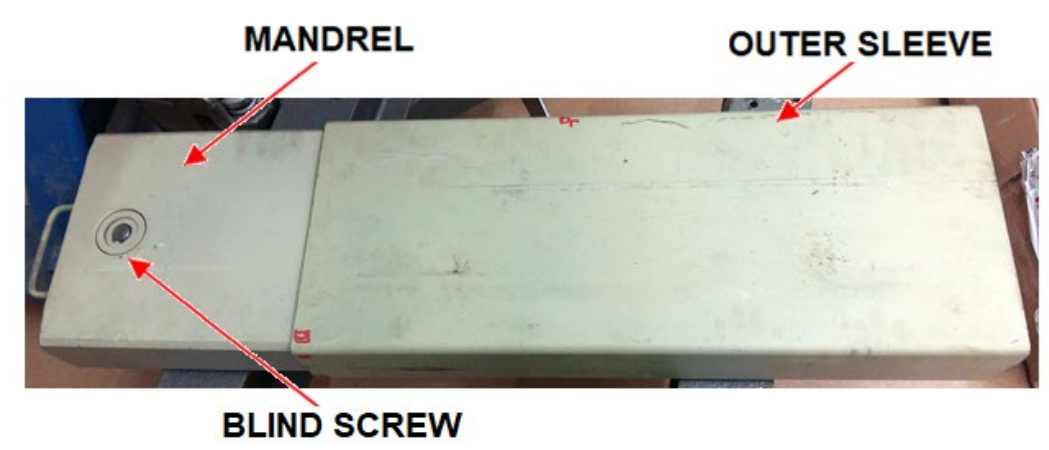

Fig. 2. The main joint of prototype floating bridge

Each connector consists of two components: a mandrel and an outer sleeve which has a closed rectangular profile. The mandrel is inserted into the sleeve of the adjacent bridge module. The blind screw is used to lock the connector elements of the adjacent module relative to each other.

The purpose of the research is to determine maps of deformation and strains on the one of the walls of the prototype connector sleeve. Using the FEM tools, the operating conditions of the joints connecting adjacent floating segments were simulated. It was established that the basic load, to which the structure is exposed, is modules. Therefore, the joint was subjected to a threepoint bending. It was assumed in the research that the maximum stress occurring in the sleeve walls during loading cannot exceed the yield strength of the 18G2A steel, from which these elements are made of.

Loading conditions similar to those found inside connectors and in the roadway surface of real prototype cassettes were mapped during the lab tests with the use of the strength testing machine. The tests involved the usage of the Instron SATEC $1200 \mathrm{kN}$ compressing machine, together with the installed three-point bending stand which is presented in Fig. 3a).

The distance between two bottom supports, with round half-shafts on the top, was equal to $945 \mathrm{~mm}$. The mandrel rested on one half-shaft support and the sleeve rested on the other one. Because of different dimensions of the connector parts, half-shafts needed to have a different height, thus, the investigated connector was placed horizontally. Both half-shafts had radius of $29 \mathrm{~mm}$. The upper punch had a radius of $140 \mathrm{~mm}$. The mandrel was extended from the sleeve outer edge by $298 \mathrm{~mm}$. Total length of the connector is equal to $1053 \mathrm{~mm}$ (Fig. 3b).

Three-point bending tests were carried out in the load-unload cycle until the maximum force of $100 \mathrm{kN}$ was reached. The loading rate was equal to $10 \mathrm{~mm} / \mathrm{min}$. The behaviour of the joint in the configurations with and without the blind screw was compared in the research.

To determine the connector elements strains at selected points, the electroresistance method was used. A spot deformation obtained from the strain gauge marked with an arrow in Fig. 4b) was supplemented with the use of the optical 3D image correlation measurement system GOM Aramis (Fig. 4a). In this manner, maps with continuous distribution of deformations and strains were obtained. For this purpose, a stochastic black and white pattern was applied on one of the sleeve surfaces (Fig. 4b). The results of Aramis were verified by a strain gauge measurement method. The developed strain maps enabled precise, qualitative and quantitative, identification of the most stressed areas on the sleeve wall during bending of the joint and evaluation of the impact of the blind screw fixing mandrel in the sleeve (Fig. 4b) on the joint behaviour during loading. 
a)
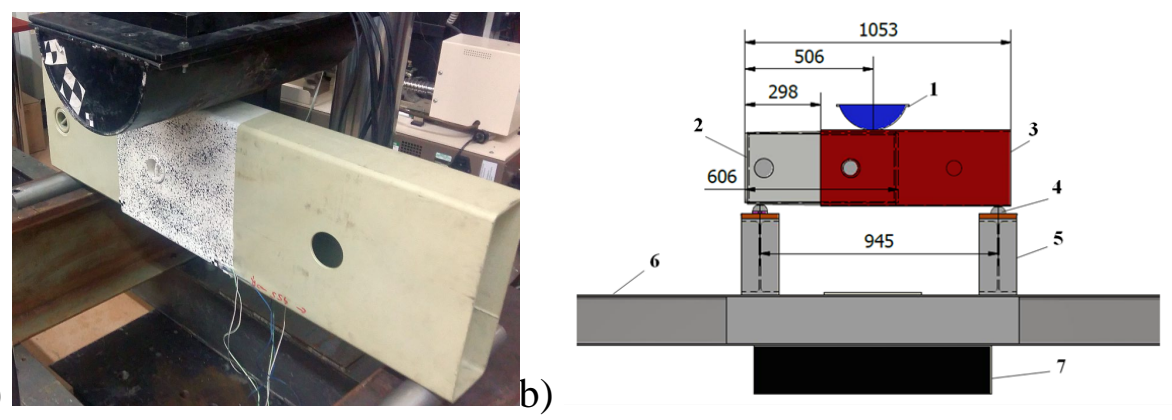

Fig. 3. The photo of the connector on the test stand (a) and the scheme of a three-point bending stand (b): 1- loading punch, 2 - mandrel, 3 - sleeve, 4 - half-shafts of the bottom support, 5 -adjusted support, 6 - I-beam of the stand, 7 -support of the testing machine

a)

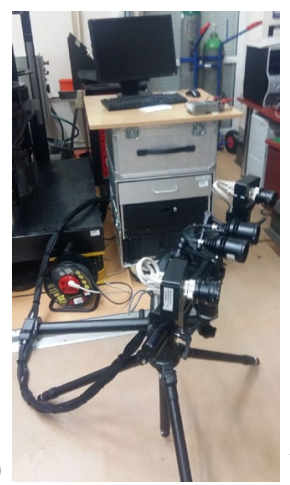

b)

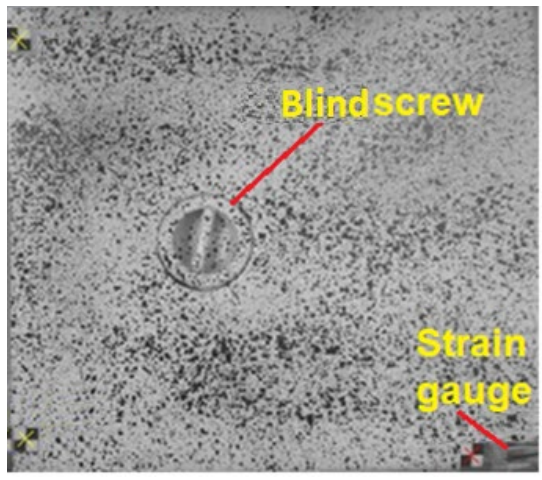

Fig. 4. Aramis optical deformation measurement system (a) and stochastic black and white pattern applied to the measuring part of the connector sleeve (b). The red arrow marks the blinds crew and the strain gauge attached near Point 2

Some areas of facets (the smallest area of the measurement in an optical deformation measurement system, equivalent to a strain gauge matrix) were marked in the Aramis software in order to obtain averaged strain curves in selected points of the sleeve. There were two points selected in the optical measurement results analysis for each evaluated configuration: one - near the blind screw hole marked as Point_1 and the other - near the strain gauge presented in Fig. 4 and marked as Point_2. The place corresponding to the strain gauge position could not be measured directly by the optical system. Therefore, comparison of both measurement methods optical and electroresistance - is only approximate. The location of Points 1 and 2 are presented in Fig. 7 and Fig. 8 for both configurations, respectively.

\section{Results of the research}

During the load-unload cycles, hysteresis loops were recorded in the case of both the conducted test variants. The maximum loading force was equal to $100 \mathrm{kN}$. The connector without the screw achieved the assumed maximum force under deflection of $3.8 \mathrm{~mm}$, while in the case of the fixed connector it was a higher value of $4.6 \mathrm{~mm}$.

The results of testing the pontoon bridge joint in the configuration without the blind screw were obtained. Three photos from the test taken by the left camera of the 3D optical deformation measurement system are presented in Fig. 5. They show pictures of the joint without the screw: before the three-point bending test (a) at the maximum load of $100 \mathrm{kN}$ (b) and at the end of the 
test (c). Generally, tests were conducted in the elastic region of the material, hence, the deformations are small. However, in some places a plastic deformation occurred.

The maps of main (major and minor) strains are shown in Fig. 6a) and b), respectively. Arrows of main directions are also shown in the pictures. The pressure of the loading stamp caused accumulation of stress near the upper surface of the connector sleeve. The area of strain concentration was marked with a red ellipse. The major strain of engineering strains in this area achieved a value of more than $0.23 \%$. The black colour is used to mark the deformation concentration around the screw fastening hole. Within this area, two points of strain concentration occurred. They were slightly distant from the horizontal symmetric axis of the hole on both its sides - Fig. 6 .

a)

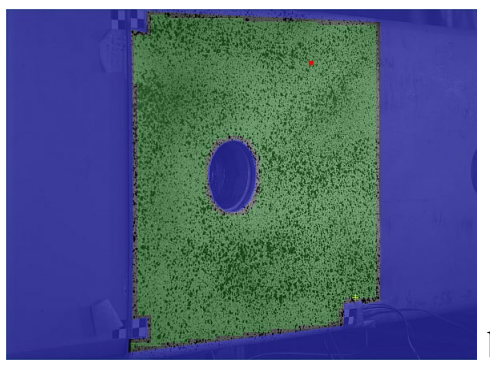

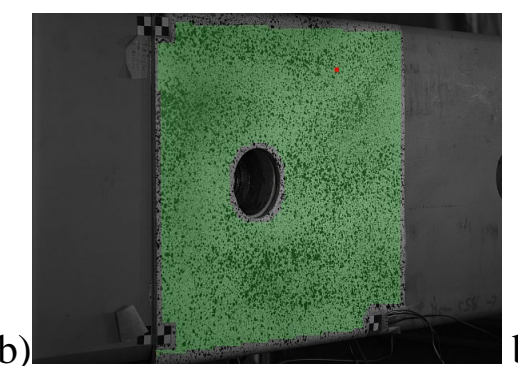

b)

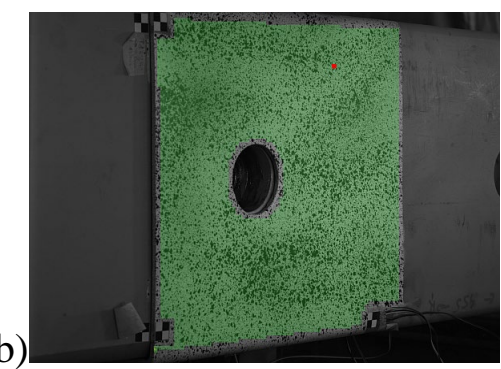

Fig. 5. Measurement area of the DIC system (marked in green) of the joint without a blind screw: a) before the test, b) at the maximum load, c) at the end of the test

a)

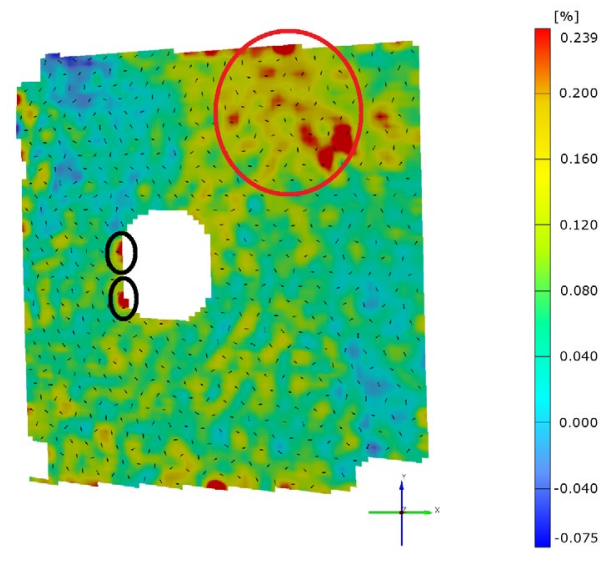

b)

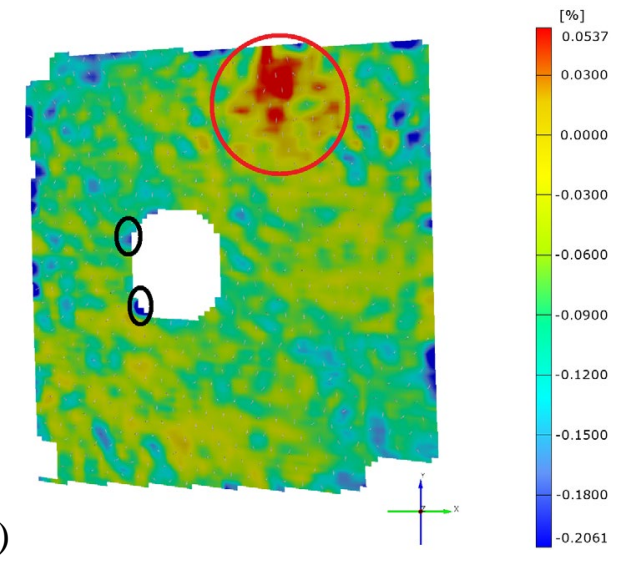

Fig. 6. Maps of the main strain distribution on the sleeve surface under maximum load for a joint with the blind screw: a) major and b) minor. Arrows of main directions are shown. Strain concentrations near the hole and near the stamp are marked with ellipses

a)

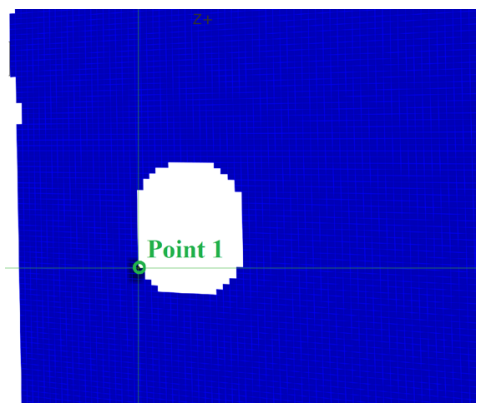

b)

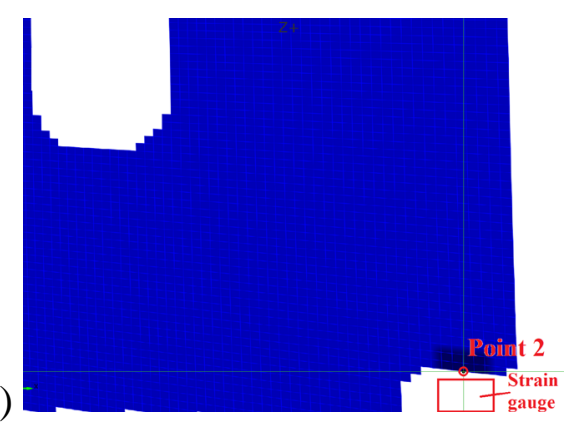

Fig. 7. The location of measurement points in the connector without a screw analysed in the 3D optical system: a) Point 1 near the screw hole; b) Point 2 near the strain gauge fixing 
a)

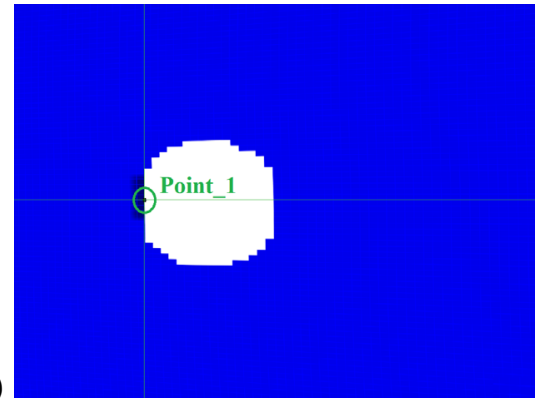

b)

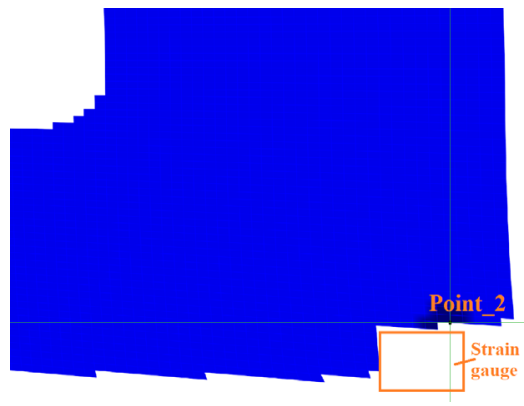

Fig. 8. The location of measurement points in the connector with the blind screw analysed in the 3D optical system: a) Point 1 near the screw hole; b) Point 2 near the strain gauge fixing

Fig. 7a) and b) presents the locations of Point 1 and 2 analysis on the optical measurement results for the joint configuration without a blind screw. Facets chosen for averaging the strains are marked in black. Point 1 is one of the points of strain concentration near the hole and Point 2 is slightly above the strain gauge measurement point marked with a red rectangular. Adequate points for the second joint configuration are presented in Fig. 8a) and b).

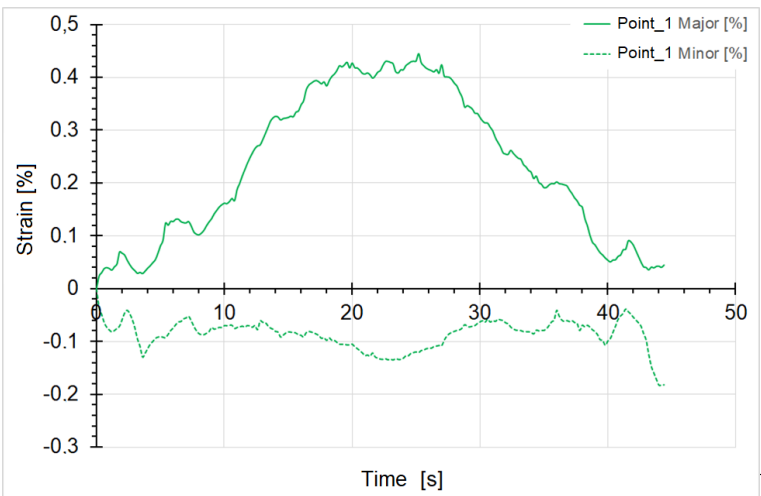

a)

Fig. 9. Major and minor strains curves as a functio

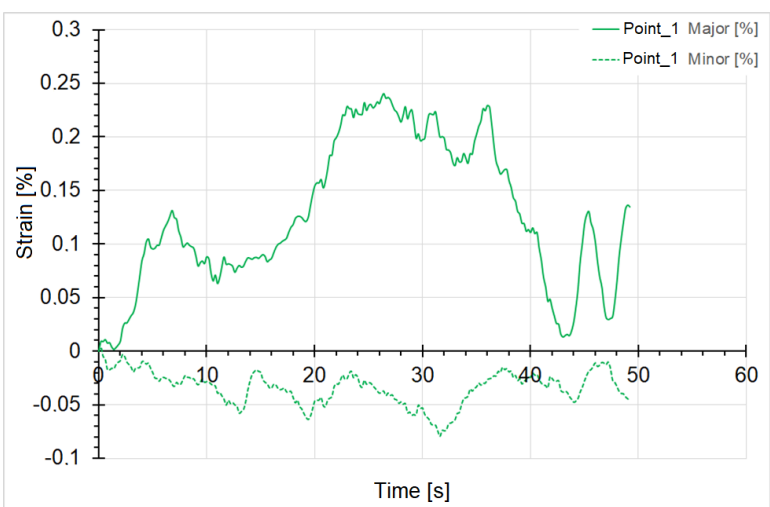
hole of the connector: a) without the screw; b) with the screw

In Fig. 9a) and b), a comparison of major and minor strains in Point 1 for both test scenarios is presented. In Point 1, near the hole without a screw, the maximum major strain averaged from the area marked in black in Fig. 7a) is equal more than $0.4 \%$, which means that plastic deformations occurred in this area. In the second loading case, the maximum major strain for the area marked in black in Fig. 8a) was equal to $0.24 \%$.

Similarly as in the case of the evaluations of the connector without a blind screw, the results of testing the pontoon bridge joint in the configuration with the blind screw are presented. Photos from the left camera of the DIC (Digital Image Correlation) system at the beginning, at the maximum load and at the end of the test are presented in Fig. 10. Next, maps of the main strains for the connector loaded with a maximum load of $100 \mathrm{kN}$ are shown in Fig. 11. As in the first scenario, strain accumulation caused by the pressure of the loading punch (marked with red ellipses) occurred on the upper surface of the connector sleeve. The black colour ellipse is the place where the strains concentrated around the hole and the screw. There is only one point of the strain concentration in this scenario and it is situated approximately on the horizontal symmetry of the hole. The presence of the locking blind screw changed the character of the strain distribution in the area of the hole. 
a)
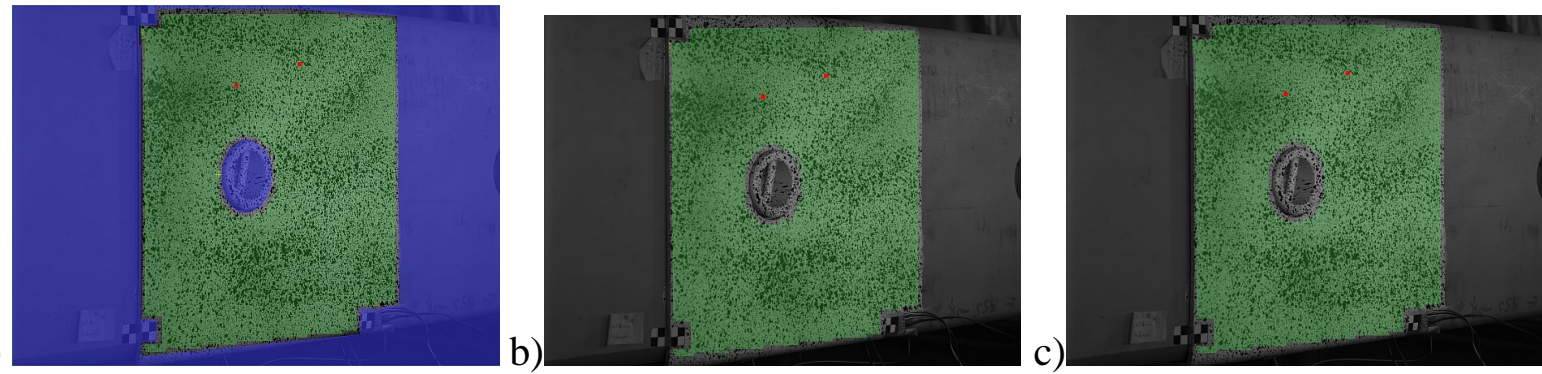

Fig. 10. Measurement area of the DIC system (marked in green) of the joint with the blind screw: a) before the test, b) at the maximum load, c) at the end of the test

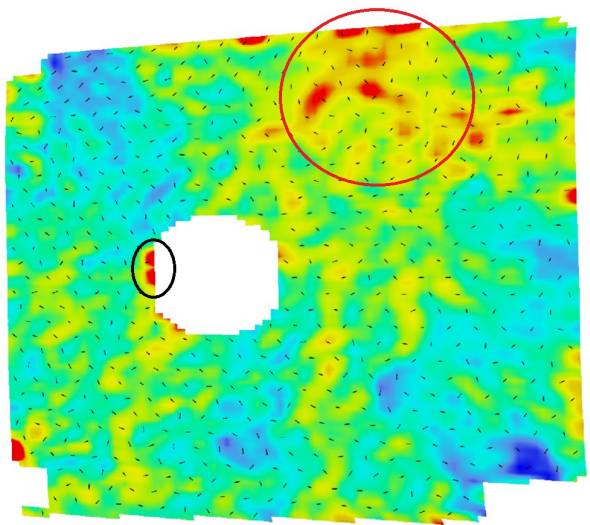

a)

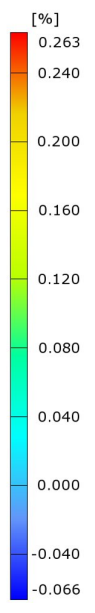

b)

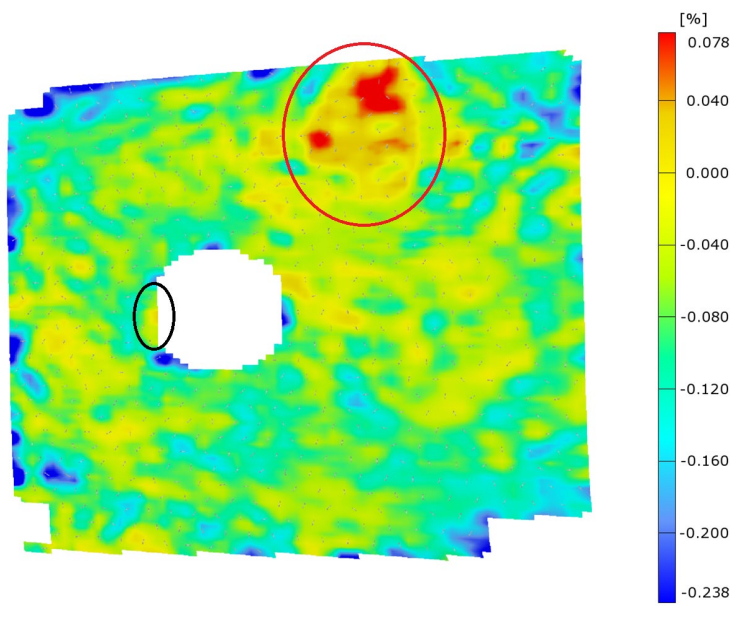

.238

Fig. 11. Maps of the main strain distribution on the sleeve surface under maximum load for a joint with the blind screw: a) major and b) minor. Arrows of main directions are shown. Strain concentrations near the hole and near the stamp are marked with ellipses

Comparison between Points 2 chosen during DIC method and strain gauge measurements are presented for both scenarios in Fig. 12a)and b) respectively. The results compliance is sufficient but not exact. It should be noted that Points 2 were situated not exactly on the strain gauge fixing point but slightly above it. Moreover, strain gauge measurement is more precise compared with the optical measurement data.

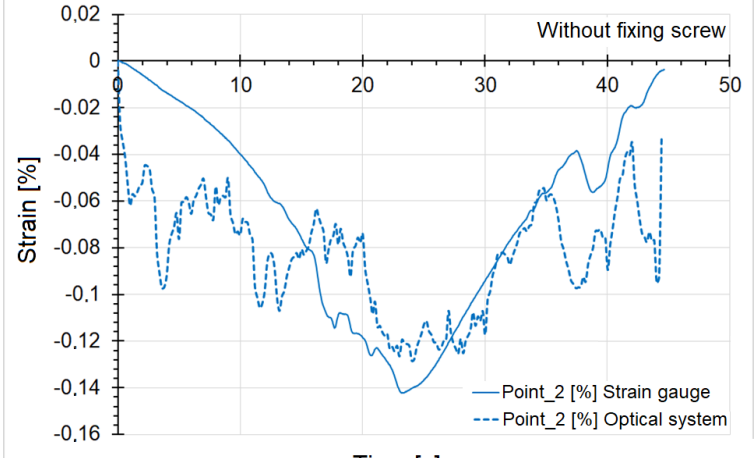

a)

Fig. 12. Comparison of measurements carried out with the DIC system in Point 2 (dotted line) and the strain gauge near Point 2 (solid line) for the connector without (a) and with (b) the 


\section{Conclusions}

Conclusions observed during three-point bending tests of the joint in configurations with and without a blind screw are as follows:

- The connector in both configurations generally worked in the elastic range of the material. However, there were areas where strain concentrations occurred in both cases. Measurements with the optical system allowed locating such places;

- The largest deformations were recorded near the place of the loading punch application on the upper surface of the sleeve and near the hole of the fastening bolt (Fig. 6 and 11);

- The nature of the deformations around the bolt hole is different for both scenarios. The presence of the blind screw interferes with the bending process and changes character of strain distribution especially near the hole. In the configuration without the screw, there are two independent foci. In the screw configuration, there is one place near the axis of symmetry;

- Maximum major strain in Point 1 is larger for configuration without the blind screw (Fig. 9a) than for the other configuration with the screw (Fig. 9b). The presence of the screw in the hole changes the nature of the connector load.

\section{Acknowledgement}

The works were carried out as part of the research project PBS 23-937, Military University of Technology, 2016-2018.

\section{References}

[1] W. Krasoń, Koncepcja, rozwiązania konstrukcyjne i badania systemu pływającego o regulowanej wyporności, rozdział w monografii. Inżynieria wojskowa - problemy i perspektywy, Wojskowy Instytut Techniki Inżynieryjnej im. profesora Józefa Kosackiego, Wrocław 2018, ISBN978-83-948983-0-4, pp. 123-146.

[2] W. Krason, J. Malachowski, Field test and numerical studies of the scissors-AVLB type bridge, Bulletin of The Polish Academy of Sciences, Technical Sciences, Vol. 62, No. 1, 2014, pp. 103-112. https://doi.org/10.2478/bpasts-2014-0012

[3] W. Krason, L. Filiks, Numerical tests of the main pin joint in scissor BLG bridge, CMM2011 - Computer Methods in Mechanics, 9-12 May 2011, Warsaw.

[4] Derewońko, W. Krasoń, Mobile pontoon bridge and floating systems, Konferencja Antwerpia, maj 2018, Special Interest Group A2 (Ports and Maritime) of the World Conference on Transport Research Society (WCTRS), conference proceedings, 3-4 May 2018, Antwerpia.

[5] European Patent, No. 2251255, A sectional pontoon bridge, Military University of Technology, 2013.

[6] Patent Office of the RP, PAT.223689, Set of mechanical locks to connect the floating bridge cassettes and the cassette opening mechanism, Military University of Technology, 2016.

[7] W. Krason, P. Slawek, Design and pre-testing of a mobile modular floating platform with adjustable displacement, Mechanik nr 11, 2017, pp.1075-1080. https://doi.org/10.17814/mechanik.2017.11.185

[8] W. Barnat, W. Krasoń, P. Bogusz, M. Stankiewicz, Experimental and numerical tests of separated side lock of intermodal wagon, Journal of KONES Powertrain and Transport, Institute of Aviation, vol. 21, no 1, pp.15-22. https://doi.org/10.5604/12314005.1134049 